\title{
Los "hombres funestos". Soldados delincuentes, redes de deserción y guerra política durante los dos primeros años del Sitio Grande de Montevideo (1843-1844)*
}

Nicolás Duffau Soto

\begin{abstract}
Afiliado institucionalmente a la Facultad de Humanidades y Ciencias de la Educación de la Universidad de la República (Uruguay). Correo electrónico: nicolasduffausoto@gmail.com. El autor es Doctor en Filosofía y Letras de la Universidad de Buenos Aires (Argentina). Recientemente ha publicado, entre otros: "Pretensiones totales, construcciones parciales. Los policías escritores y la historia sobre la Policía decimonónica (1980-2018)", Claves. Revista de Historia, Montevideo, Vol. 4 No. 6 (2018); "La Policía en la Provincia Oriental (1826-1838). Una construcción institucional entre el Antiguo Régimen y el orden público”, Anuario IEHS, Tandil, Vol. 1 No. 33 (2018), y en coautoría "Redes de espionaje y conspiraciones durante el inicio del Sitio Grande. Montevideo, 1843", Anuario Colombiano de Historia Social y de la Cultura, Vol. II y No. 46 (2019). Su tema de interés es Construcción estatal en el siglo XIX.
\end{abstract}

Recibido: 19 de marzo de 2019

Aprobado: 10 de noviembre de 2019

Modificado: 20 de noviembre de 2019

Artículo de investigación científica

DOI: http://dx.doi.org/10.15648/hc.36.2020.3

Este artículo forma parte del proyecto "Claves de la construcción del Estado Oriental. Milicias, territorio y orden político (1830-1875)" financiado por la Universidad de la República (Uruguay). Esta publicación está bajo una licencia Creative Commons Reconocimiento-NoComercial 4.0 
Los "hombres funestos". Soldados delincuentes, redes de deserción y guerra política durante los dos primeros años del Sitio Grande de Montevideo (1843-1844)

\title{
Resumen
}

El artículo parte del caso de algunos desertores militares que durante la Guerra Grande (1838-1852) y en los dos primeros años del sitio de Montevideo (18431844), abandonaron el ejército gubernamental y se unieron a las filas que asediaban la ciudad. La particularidad es que esas personas se encontraban procesadas por la justicia criminal por algún tipo de delito. A partir del caso de los delincuentes soldados -y de su uso propagandístico- buscaremos hallar fragmentos de redes que hicieron de la deserción un negocio y cuyo análisis contribuye a entender la situación de las fuerzas en armas durante los dos primeros años del sitio.

Palabras clave: guerra grande, fuerzas en armas, soldados, delincuentes

"Fatal men". Criminal soldiers, desertion networks and political warfare during the first two years of the Siege Grande of Montevideo (1843-1844)

\begin{abstract}
The article focuses on the case of some military deserters during the Guerra Grande (1838-1852) and in the first two years of the siege of Montevideo (18431844). This people left the government army and joined the ranks that besieged the city. The peculiarity of these people is that they were criminals. In relation to the criminal soldiers' case -and the propaganda about them- we will look for fragments of networks that made the desertion a business. This analysis helps to understand the situation of the armed forces during the first two years of the siege.
\end{abstract}

Keywords: Guerra Grande, army, soldiers, criminals.

Os "homens funestos". Soldados delinquentes, redes de deserção e disputa política durante os dois primeiros anos da Grande Guerra de Montevidéu (1843-1844)

\section{Resumo}

$\mathrm{O}$ artigo parte do caso de alguns desertores militares que durante a Grande Guerra (1838-1852) e nos dois primeiros anos da operação militar de Montevidéu (1843- 
1844), deixaram o exército governamental e se uniram às fileiras que cercavam a cidade. A peculiaridade é que essas pessoas estavam sendo processadas pelo sistema de justiça por algum tipo de crime. A partir do caso dos soldados delinquentes - e seu uso propagandista - procuraremos fragmentos de redes que fizeram da deserção um negócio e cuja análise contribui para entender a situação das forças armadas durante os dois primeiros anos do cerco.

Palavras-chave: Grande Guerra, Forças Armadas, soldados, delinquentes

\section{"Les hommes funestes". Soldats criminels, réseaux de désertion et guerre politique pendant les deux premières années du Grand Siège de Montevideo (1843-1844).}

\section{Résumé}

L'article part du cas de certains passés militaires qui pendant la Grande Guerre (1838-1852) et au cours des deux premières années du siège de Montevideo (18431844) quittèrent l'armée gouvernementale et rejoignirent les rangs qui assiégeaient la ville. Ces personnes étaient procésés par le système de justice pénale pour différent types de crimes. Dans le cas des soldats délinquants - et de leur utilisation à des fins de propagande -, nous chercherons des fragments de réseaux qui ont fait de la désertion une entreprise et dont l'analyse permet de comprendre la situation des forces armées pendant les deux premières années du siège.

Mots-clés: grande guerre, forces armées, soldats, criminels

\section{INTRODUCCIÓN}

El episodio conocido como Guerra Grande, fue un conflicto bélico de carácter regional que durante casi quince años (1838-1852) involucró a las principales provincias de la región platense y a los intereses británicos y franceses en el Río de la Plata. La guerra se originó en 1838 cuando el ex presidente oriental Fructuoso Rivera se sublevó, con apoyo de unitarios argentinos y la armada francesa, contra el gobierno de Manuel Oribe, quien contó con el apoyo de Juan Manuel de Rosas, gobernador de la Provincia de Buenos Aires. A partir de 1838 distintas batallas y acuerdos entre grupos y facciones, fueron moldeando la vida política de la zona, que tuvo un momento central en febrero de 1843 cuando el 
denominado Ejército Unido de Vanguardia de la Confederación Argentina, comandado por Oribe, sitió la ciudad de Montevideo.

El asedio de la ciudad, que se inició el 16 de febrero de 1843 y se prolongó hasta octubre de 1851, provocó la convivencia en el Estado Oriental del Uruguay de dos gobiernos, uno sitiado en Montevideo y su línea defensiva - denominado por la historiografía como gobierno de la Defensa- y el otro, conocido como del Cerrito - por la zona en que se ubicó-, que en el correr de la década de 1840 controló los extramuros de la ciudad y la mayor parte del territorio (salvo la capital y Colonia del Sacramento) y contó con sus órganos representativos y de administración, oficinas fiscales, entidades educativas y aduana.

La guerra inició un proceso de permanente movilización militar. Entre las primeras medidas adoptadas por el gobierno de Montevideo -en diciembre de 1842 tras la derrota que precipitó el sitio a la ciudad- se incluye la abolición de la esclavitud y la incorporación de los libertos en el servicio de las armas, la creación de un ejército de reserva, nuevos batallones y la movilización de distintos contingentes armados de carácter miliciano. Se estima que en los primeros meses de 1843, Montevideo contó con unos 6.000 efectivos $^{1}$, a los que se podrían agregar aquellos que se encontraban en el resto del territorio ${ }^{2}$. El ejército comandado por Oribe estaba formado por tropas orientales, de Buenos Aires y Entre Ríos, cuyo número ascendía a 7.000 hombres $^{3}$. No obstante, las fuerzas sitiadoras debían liberar contingentes militares del Ejército Unido de Vanguardia de la Confederación Argentina comprometidos con la movilización militar en la guerra que Buenos Aires llevaba adelante contra otras provincias.

1 Mario Etchechury, “Defensores de la humanidad y la civilización’. Las legiones extranjeras de Montevideo, entre el mito cosmopolita y la eclosión de las nacionalidades (1838-1851)", Historia 50.2 (2017): 491-524.

2 Eduardo Acevedo fija ese número en 6.000 soldados, aunque también da cuenta de otras estimaciones que bajan el total a 1000 hombres. Cuando Rivera arribó a Montevideo a fines de enero de 1843 se estima que contaba con 4.500 hombres. Véase Eduardo Acevedo, Anales históricos del Uruguay. (Montevideo: Barreiro y Ramos, 1933, vol. II), 100-102.

3 Ana Frega, "La vida política", en Historia contemporánea del Uruguay. 1808-1880, ed. Ana Frega (Montevideo: Fundación MAPFRE-Planeta, 2016, vol. I), 77. 
El 5 de enero de 1843 el Poder Ejecutivo radicado en Montevideo dispuso que para defender Montevideo era necesario "poner en armas todos los medios y elementos q.e. presenta la cap.l p.a. preservarla de caer en poder del enemigo". "En ese contexto la necesidad de contar con hombres para las armas se tornó una situación acuciante y los jefes militares se vieron en la obligación de tener que recurrir a distintos mecanismos que permitieran engrosar el número de integrantes de las fuerzas de guerra. Una de las modalidades fue explotar el uso del ejército como un espacio para purgar penas delictivas, aunque esta posibilidad no resulta privativa del período. Desde el período colonial y, por lo menos, hasta la década de 1880, la remisión de delincuentes fue una práctica habitual en las fuerzas en armas que actuaron en territorio oriental. En sociedades donde no había una codificación penal precisa, el cumplimiento de tareas militares era una forma usada para que los hombres pudieran "borrar" los antecedentes penales.

En los primeros dos años del sitio -donde el asedio fue más férreo y la posibilidad de un triunfo oribista generó alarma en la población de Montevideo- un número indeterminado de delincuentes comunes fueron incorporados a las tropas militares, en especial de Infantería ${ }^{5}$. Estos delincuentes -cuyos casos estudiaremos- habrían gozado de una especie de libertad anticipada, promovida por las autoridades de la defensa de Montevideo, gracias a la cual se incorporaron a la línea defensiva y posteriormente se convirtieron en desertores pasados hacia el Cerrito ${ }^{6}$. Este artículo aborda algunos de esos casos de delincuentes comunes militarizados en el bienio 1843-1844, que pasaron al bando enemigo a

4 Archivo General de la Nación, Documentos de la Administración Central, Ministerio de Gobierno (en adelante AGN-MG), caja 942, carpeta 5, documento 343 [Documento del Poder Ejecutivo a la Honorable Asamblea Legislativa, 3 de enero de 1843]. Nota: q.e.: que; cap.l: capital; p.a: para.

5 Los delincuentes no fueron ajenos a la guerra, en sociedades donde la militarización fue un fenómeno estructural y estructurante. Sobre la militarización social del período véase Raúl Fradkin, "Guerra y sociedad en el litoral rioplatense en la primera mitad del siglo XIX", en Las fuerzas de la guerra en la construcción del Estado: América Latina, siglo XIX, eds., Juan Carlos Garavaglia, Juan Pro Ruiz, Eduardo Zimmermann (Rosario: Prohistoria, 2012) 319-356; Alejandro Rabinovich, La société guerrière. Pratiques, discours et valeurs militaires dans le Rio de la Plata, 1806-1852. (Rennes: Presses Universitaires de Rennes, 2013).

6 Sobre la relación entre deserción e identidades políticas (en especial de los sectores populares) seguimos a Alejandro Rabinovich, "El fenómeno de la deserción en las guerras de la revolución e independencia del Río de la Plata: 1810-1829”, EIAL, Vol. 22 No. 1, (2011): 33-56. 
través de la deserción. La posibilidad de regresar a prisión y la ausencia de expectativas en torno al desenlace de un conflicto, que en un primer momento parecía inclinarse hacia el bando sitiador, los llevaron a abandonar la defensa y pasar al Cerrito. La situación abrió distintas acusaciones entre los medios de prensa de uno u otro bando. Los delincuentes / soldados y desertores pasaron a ser figuras contenciosas y rápidamente politizadas a través de los testimonios editados por distintas publicaciones periódicas.

Al analizar la papelería del período es posible observar que la afluencia de hombres considerados de "dudosa" moralidad o con un pasado vinculado a algún delito, era una preocupación constante de los altos mandos militares de Montevideo. Los ejemplos usados, más la postura de algunas autoridades montevideanas, permitirán también aproximarse al estudio de las redes formadas por intermediarios que, sin hacer directamente la guerra, participaron de la misma a través de mecanismos que favorecían la deserción. Esos mecanismos podían ir desde la falsificación de pasaportes o el conocimiento de pasos clandestinos que permitían salir de la zona sitiada y pasar al bando enemigo. Se trata de pistas fragmentarias e inconexas pero interesantes en la medida que permitirán comprender rasgos del contexto y profundizar en algunas de las características que presentaron las fuerzas en armas. Consideramos que la tensión entre el ejemplo y el contexto puede generar resultados satisfactorios para entender uno de los episodios militares más importantes de la región durante el siglo XIX.

El trabajo se inserta en una serie de abordajes recientes que han focalizado su atención en el rol de las fuerzas en armas y han profundizado en distintos estudios de caso que involucran a la región iberoamerica$\mathrm{na}^{7}$. En varios de esos trabajos se insistió en la idea según la cual los

7 Este campo tiene un punto de partida importante en las discusiones iniciadas a partir de la publicación de Bandidos de Eric Hobsbawm en 1969 y las sucesivas respuestas que desencadenó, en especial aquellas que se concentraron en el debate sobre el rol atribuido a los sujetos que participaban de acciones bélicas, pero también cometían distintos hurtos, robos u atropellos, Eric Hobsbawm, Bandidos (Barcelona: Crítica, 2003); las respuestas en Anton Blok, "The Peasant and the Brigand: Social Banditry Reconsidered", Comparative Studies in Society and History, vol. Vol. 14 No. 4 (1972): 494-503; Pat O’Malley, "Social Bandits, Modern Capitalism, and the Traditional Peasantry: A Critique of Hobsbawm”, Journal of Peasant Studies, Vol. 6 No. 4 (1979): 489-501; Richard Slatta, (ed), 
ejércitos constituyeron espacios de conflicto, negociación y protesta, en los que la autoridad fue desafiada en forma individual o colectiva. Sin embargo, en el caso uruguayo, salvo abordajes parciales $^{8}$, la historiografía aún no ha avanzado en un mejor conocimiento de las fuerzas en armas involucradas durante la Guerra Grande, o siquiera en un mejor conocimiento del período?. Tampoco se cuenta con trabajos sostenidos específicos sobre la deserción en la Banda Oriental o en el período posterior a las guerras de independencia ${ }^{10}$. En buena medida aún impera la visión según la cual “el ambiente permisivo y casi de anomia de los nue-

Bandidos. The varieties of Latin American Banditry (New York: Greenwood Press, 1987). A ello deberíamos agregar el cruce con una historiografía regional reciente sobre las fuerzas en armas en la que destacan, entre otros, los trabajos de Juan Carlos Garavaglia, Raúl Fradkin, Jorge Gelman, Hilda Sabato, Ricardo Salvatore, Alejandro Rabinovich, Gabriel Di Meglio, Flavia Macias, Alejandro Morea o Luciano Literas, entre otros, para el caso argentino y José Irán Ribeiro, Celso Castro, Vitor Izeckshon, André Fertig, Adriano Comissoli, para el caso brasileño. Un trabajo que sintetiza investigaciones de algunos de los autores mencionados en Juan Carlos Garavaglia, Juan Pro Ruiz, Eduardo Zimmermann, Las fuerzas de la guerra; Eduardo Santos Neumann, Luis Alberto Grijó, (orgs.) O continente em armas: uma historia da guerra no sul do Brasil. (Rio de Janeiro: Apicuri, 2010). $\mathrm{Al}$ respecto véase Mario Etchechury, "De colonos y súbditos extranjeros a «ciudadanos en armas». Militarización y lealtades políticas de los españoles residentes en Montevideo, 1838-1845", Revista Universitaria de Historia Militar, Vol. 4 (2015): 119-142; Mario Etchechury "'Defensores..."; Mario Etchechury Barrera, 'Chinas, guayaquises y jente que no es de armas'. Algunas consideraciones sobre el impacto social de la guerra en Montevideo y su hinterland rural (1842-1845)", Prohistoria 20.28 (2017): 129-147; Mario Etchechury, "Aventureros, emigrados y cosmopolitas. Hacia una historia global de las guerras en el Río de la Plata (1836-1852)", Polhis, No. 20 (2017): 22-52. Otro trabajo importante sobre la relación entre redes esclavistas, abolición y militarización de los afrodescendientes en Alex Borucki, From Shipmates to Soldiers: Emerging Black Identities in the Rio de la Plata (Albuquerque: University of New Mexico Press, 2015).

9 La versión canónica sigue siendo la de Juan E. Pivel Devoto, a través de su estudio de los partidos políticos o en su trabajo específico, escrito en coautoría con Alcira Ranieri de Pivel Devoto, en el que presenta el conflicto como un episodio con características exclusivamente nacionales y a Juan Manuel de Rosas como un poder invasor que desconoció la soberanía uruguaya; a su vez establece una periodización vinculada a lo militar que finaliza en 1851 con los acuerdos de paz y no en 1852 con la derrota definitiva de Rosas. Los partidos son presentados como un grupo homogéneo y fácilmente diferenciable, cuando en realidad podríamos referirnos a una coalición de diversos sectores político-militares que fueron modificando sus posiciones conforme transcurría la guerra. Véase Juan E. Pivel Devoto, Alcira Ranieri de Pivel Devoto, La Guerra Grande. 1839-1851 (Montevideo: Medina, 1971); Juan E. Pivel Devoto, Historia de los partidos políticos en el Uruguay (Montevideo, Atlántida: 1942, tomo I).

10 Una referencia en ese sentido en Daniel Fessler, “Armas y control. El "negro delito de la deserción” en la Banda Oriental (1811-1816)", eds., Paulo Possamai, Emir Reitano, Hombres, poder y conflicto. Estudios sobre la frontera colonial sudamericana y su crisis (La Plata: Universidad Nacional de la Plata, 2015) 388-415; Daniel Fessler, "Desertores: entre el castigo y el indulto", coord.., Ana Frega, Los orientales en armas. Estudios sobre la experiencia militar en la revolución artiguista (Montevideo: Universidad de la República, 2015), 29-53. 
vos Estados" facilitaba la deserción porque favorecía "un romanticismo libertario opuesto a toda forma de autoridad o simplemente de regulación de la vida social, que propiciaba desbordes y desórdenes" ${ }^{11}$. Por el contrario, consideramos que la deserción no se explica sólo como parte de un romanticismo libertario, sino que es posible encontrar canales de circulación de hombres capaces de mostrar situaciones sociales pasibles de ser complejizadas. La crítica y revisión a los enfoques más tradicionales ha permitido que nuevas miradas redescubrieran documentación de guerra, gobierno y expedientes judiciales que favorecieron otro tipo de abordajes que apuntan a analizar los fenómenos bélicos en su dimensión social y no a realizar una historia bélica encerrada en batallas. Seguimos a Eduardo Zimmermann, quien se ha referido a la importancia de estudiar las "zonas grises" de la estatidad que permitirían encontrar redes de relaciones que den cuenta de procesos de construcción estatal paralelos, ajenos a una lógica de racionalización centralizada de los recursos ${ }^{12}$. Resulta fundamental tratar de incorporar el análisis de los intersticios en los cuales las manifestaciones del poder estatal -como es el caso de un ejército en guerra- fallan. El cruce entre la pretensión de control y la falla (en este caso la existencia de delincuentes o la deserción en una fuerza del “orden”) torna más complejos los análisis lineales que presentan las guerras como el mero enfrentamiento entre dos bandos.

En el artículo se trabajará con fuentes históricas primarias provenientes de archivos administrativos, judiciales, memorias militares y prensa de la época, que nos permitirán una aproximación al fenómeno de la deser-

11 Oscar Abadie-Aicardi, "Levas y deserciones de marineros extranjeros en los orígenes de la Armada Nacional (1830-1840)", Humanidades. Revista de la Universidad de Montevideo, No. 3 (2003): 106. En los últimos años distintos trabajos enmarcados en la historiografía regional han avanzado en comprender la deserción como un fenómeno complejo y han superado las interpretaciones más tradicionales. Al respecto véase Seth Meisel, "The Politics of Seduction: Mutiny and Desertion in Early Nineteenth-Century Cordoba", ed. Jane Hathaway, Rebellion, Repression, Reinvention: Mutiny in Comparative Perspective (Westport: Praeger, 2001), 131-144. Sin trabajar estrictamente el tema de la deserción, en forma reciente Florencia Thul, estudió el fenómeno de los soldados sitiados en Montevideo que en su tiempo libre se incorporaron como jornaleros a distintas actividades laborales. Florencia Thul, "Mercado de trabajo y movilización militar en Montevideo sitiada (1838-1851), Claves. Revista de Historia, Vol. 5 No. 8 (2019): 7-34.

12 Eduardo Zimmermann, "Guerra, fuerzas militares y construcción estatal en el Río de la Plata, siglo XIX. Un comentario", en Juan Carlos Garavaglia, Juan Pro Ruiz, Eduardo Zimmermann, Las fuerzas de la guerra..., 189 . 
ción, en especial en los casos en los que la persona involucrada también tenía un pasado delictivo.

\section{Tres (nuevos) soldados En busca de una biografía}

La Gaceta Mercantil, uno de los voceros oficiosos del gobierno de Juan Manuel de Rosas ${ }^{13}$, estilaba publicar en su gacetilla distintas noticias sobre la situación del ejército sitiador de Montevideo. Eso incluía reportes de operaciones militares -siempre con la prudencia que implicaba informar sobre la estrategia bélica-, declaraciones de personas apresadas por el gobierno de la defensa o pasados militares, así como información acerca de nuevos integrantes de los contingentes militares ${ }^{14}$. En su edición del 12 de febrero de 1844, La Gaceta informó sobre la incorporación al Ejército Unido de Vanguardia de Francisco González, Manuel Guerrero y Francisco Real ${ }^{15}$. En la declaración publicada, González, presentado como subteniente del $6^{\circ}$ batallón de infantería y pasado hacia el Cerrito el $1^{\circ}$ de febrero de 1844 , reafirmaba que era un desertor convencido que la causa de los sitiadores era "justa" porque el gobierno montevideano era "tan bárbaro como absoluto." Esto llevaba, siempre siguiendo a González, a que un importante número de soldados quisieran fugar de la ciudad ${ }^{16}$.

Real presentó un panorama sombrío relativo "al estado de la plaza de Montevideo, y la horda que por desgracia aún existe en aquel punto, y a la que he tenido la fatalidad de pertenecer". La población "sufre actualmente la mayor escasez, por la casi total falta de los principales artículos de manutención, notándose en la clase de naturales una suma de indigencia”. La Gaceta celebró el pasaje de Real como una demostración de "la considerable deserción de la guarnición sitiada de Montevideo, que continúa sin interrupción aun en la clase de Oficiales" como con-

13 Jorge Myers, Orden y virtud. El discurso republicano en el régimen rosista (Buenos Aires: Universidad Nacional de Quilmes, 1995), 32.

14 Una síntesis del contenido de la publicación en Antonio Zinny, La Gaceta mercantil de Buenos Aires 1823-1852 resumen de su contenido con relación a la parte americana y con especialidad á la historia de la República Argentina (Buenos Aires: Imprenta Americana, 1875); un análisis de su contenido en Jorge Myers, Orden y virtud, 32.

15 La Gaceta Mercantil. Diario comercial, político y literario (Buenos Aires, 12 de febrero de 1844), 1-3.

16 La Gaceta Mercantil. Diario comercial, político y literario (Buenos Aires: 12 de febrero de 1844), 1. 
secuencia del descontento generado por la actitud de las autoridades montevideanas y su sometimiento a las fuerzas británicas apostadas en el puerto de la ciudad ${ }^{17}$.

Por último, Manuel Guerrero, en carta escrita directamente a Oribe, se presentó como "víctima de infames manejos y de pérfidos engaños, en pos de los que he sufrido una terrible persecución por los hombres funestos del círculo del Degollador Rivera”. En la nota reconoció haber estado preso desde diciembre de 1842 por haberse negado a incorporarse al ejército. A su vez aprovechó para realizar otros cuestionamientos a distintas figuras de la defensa, opositoras al rosismo; entre ellas José Rivera Indarte a quien acusó de comandar la policía secreta ${ }^{18}$.

En esas declaraciones no había nada extraño. Hasta ahí era una estrategia de propaganda, frecuente en el período, en las que uno o más desertores brindaban un testimonio (presentado como símil a una declaración judicial) e información de interés que dejaba en evidencia al enemigo. Más común aún en Montevideo, ya que durante los dos primeros años del sitio a la ciudad hubo un importante número de hombres que pasaban de un bando a otro de las fuerzas en conflicto. Mateo Magariños de Melo, en su trabajo dedicado al gobierno del Cerrito, sostuvo que entre marzo de 1843 y mayo de 1846 cerca de 2.100 combatientes de Montevideo pasaron de la ciudad al territorio ocupado por las fuerzas sitiadoras ${ }^{19}$. Según Tomás de Iriarte, esos desertores recibían un trato "inhumano" y eran "destinados con un fusil a las escuchas de la línea exterior." ${ }^{20}$ En esa dirección también se expresó en sus memorias Francisco Agustín Wright, quien se refirió al carácter zafral de la

17 La Gaceta Mercantil. Diario comercial, político y literario (Buenos Aires: 12 de febrero de 1844), 1.

18 La Gaceta Mercantil. Diario comercial, político y literario (Buenos Aires: 12 de febrero de 1844), 2, 3.

19 Mateo Magariños de Mello, El Gobierno del Cerrito (Montevideo: s.d., 1961, tomo II), 861-863. Mario Etchechury estudió el fenómeno de los pasados del Cerrito a Montevideo y el uso de sus relatos como propaganda. Véase “"Visto y oído”. El testimonio de los prisioneros de guerra: de la experiencia del combate a la propaganda bélica (Río de la Plata, 1839-1845)”, en Guerras civiles. Un enfoque para entender la política en Iberoamérica (1830-1935), ed. Laura Reali, (Madrid: Estudios de AHILA, 2019), 89-106.

20 Tomás de Iriarte, El sitio de Montevideo y la política internacional en el Río de la Plata (Buenos Aires: Ediciones Argentina, 1951), 330, 331. 
actividad militar, ya que "ser soldado es una ocupación momentánea en que se cambia el arado o los instrumentos industriales por el fusil.” Eso llevaba, según Wright, a que los ejércitos se poblaran de personas que buscaban un rédito económico inmediato o veían la actividad militar como un complemento de otras actividades. Ante la adversidad muchas de esas personas buscaban escapar de las obligaciones militares ${ }^{21}$.

En este tipo de testimonios, que se podrían complementar con otros del período, queda en evidencia que la deserción resultó un fenómeno recurrente, por lo que no sería de extrañar que entre los soldados que escapaban de un territorio a otro también se pudieran encontrar delincuentes comunes que habían sido enviados a la línea militar. Más en un contexto en el cual los brazos para la guerra resultaban fundamentales. De acuerdo a las memorias de César Díaz la defensa se comenzó a preparar con "[c]ien soldados de línea en instrucción y que aún no habían hecho ejercicio de fuego, mil quinientos milicianos recientemente enrolados" de los cuales "dos terceras partes al menos no sabían hacer uso del fúsil", así como "seis piezas de artillería sin artilleros." Esa era “toda la fuerza y el material con que contaba la capital"22.

La necesidad de hombres y la afluencia de soldados de un lugar a otro provocaron distintas situaciones vinculadas a la indisciplina, que fueron alertadas tanto en Montevideo como en el Cerrito. Magariños de Mello se encargó de recopilar parte de las quejas de los comandantes o jefes militares del Cerrito, por los robos e indisciplinas que cometían los soldados ${ }^{23}$. Urgidos de soldados, señala el mismo historiador, fue que las autoridades del Cerrito decidieron aplicar una recluta voluntaria y otro forzada. Este último sistema "se llama generalmente destino" y era empleado "como castigo a un delincuente, o a un individuo cualquiera que se encuentre en determinada situación, tal como un prisionero, etc." Bajo el gobierno de Oribe el sistema fundamental fue "el

21 [Francisco Agustín Wright], Montevideo. Apuntes históricos de la defensa de la república (Montevideo: Imprenta del Nacional, 1845), 7, 8.

22 César Díaz, Memorias del Gral. César Díaz (Montevideo: Ministerio de Instrucción Pública, 1968), 26.

23 Magariños de Mello, El gobierno del Cerrito, 736-738. 
destino para los Cuerpos de Línea"24. Por ello, podríamos pensar que un indeterminado número de delincuentes se plegaron a las facciones en guerra. Esta situación no resulta privativa del período, e incluso ha llevado a que distintos abordajes historiográficos analicen "la imposibilidad de [contar con] un ejército profesional" durante buena parte del siglo XIX ${ }^{25}$.

\section{Los SOLDADOS-DELINCUENTES}

El 26 de febrero de 1844 el diario de la defensa El Nacional se refirió a las "[a]dquisiciones del degollador Rosas", con particular énfasis en Francisco Real y Manuel Guerrero, quienes fueron presentados como delincuentes comunes incorporados al ejército de modo forzoso y a la postre fugados de la ciudad"26. Según el diario, Real era un "asesino conocido, que mato por la espalda [de una puñalada] a un vecino de Montevideo", hecho por el cual tenía "causa abierta en el juzgado del crimen de esta capital” y se encontraba preso. Su incorporación al ejército de la defensa se debía a la necesidad de contar con hombres, para lo que se había destinado a un grupo de "criminales" para "los servicios más peligrosos y especiales de la Linea de Fortificacion." Su delito no había sido conmutado y la salida era parte de una disposición transitoria "sin que ella prejuzgase los justos derechos de sus víctimas." Durante su desempeño en la línea sitiadora, Real se había caracterizado por una notoria "mala conducta" y "ecsesos de ebriedad a que se entregaba" que "lo habian hecho indigno del favor que le habia dispensado el gobierno, y parecia casi inevitable el volverlo al calabozo de que se le habia sacado." Para la publicación, la deserción de Real no era por convicción política, sino una estrategia para evitar ser remitido nuevamente a la cárcel pública.

El diario buscó presentar al "verdadero" Francisco Real y aprovechó para cuestionar la situación en el campo sitiador. Al parecer Real se hacimiento de procedimientos burocráticos en las fuerzas del Río de la Plata. 1810-1830”, Quinto Sol, Vol. 17 No. 1 (2013). https://cerac.unlpam.edu.ar/index.php/quintosol/article/view/597 El Nacional (Montevideo: 26 de febrero de 1844), 3. 
bía encontrado con el propio Oribe quien "le estrecho afectuosamente la mano" y "le prometió que entrando en la plaza se haría que desapareciesen los papeles en que consta su muchachada." De este modo, Oribe era presentado como un jefe dispuesto a dialogar con asesinos, que consideraba una muerte violenta como una "muchachada". A su vez la publicación apuntaba contra Rosas, quien "ha aprobado completamente la conducta de Oribe". Rosas "dice que" Real es hombre seguro y federal de esperanzas." Con ironía, el diario sostenía que la virtud de Real era "dejar muerto a un hombre de una puñalada" por lo que podría prestar" grandes servicios a la mashorca" 27 .

El otro caso era el de Manuel Guerrero, proveniente de España, sobre quien no pesaba una acusación de asesinato o robo sino de "bigamia", que fue explotada por la publicación como otro ejemplo de la decadencia y falta de moralidad que expresaba el rosismo. Las declaraciones no solo apuntaron a recoger el testimonio, también buscaron convertirse en propaganda moral para atacar al bando enemigo 28 . Guerrero, el "infame bígamo", formaba parte del ejército de la defensa y había sido apresado mientras se encontraba en funciones. Al no ser considerado "digno de seguir con un puesto activo en el ejército, estando encausado por bigamia, se le concedió el que sirviera de vigilante secreto de Policía"29. A eso se agregaba que Guerrero había oficiado como corsario en la guerra marítima y puesto a disposición un barco con documentación adulterada, luego de saquear varias embarcaciones procedentes de Buenos Aires. Al igual que a Real, según El Nacional, Oribe había prometido a Guerrero "quemar" su expediente una vez que ingresara en Montevideo.

Claramente El Nacional buscó mostrar a las fuerzas comandadas por Oribe como un ejército falto de moral y poblado por delincuentes. Durante el período en que El Nacional se publicó ${ }^{30}$ fueron frecuentes las

27 El Nacional (Montevideo: 26 de febrero de 1844), 3.

28 Muy a tono con algunas de las publicaciones del período como Muera Rosas (1841-1843) o el libro de José Rivera Indarte, Rosas y sus opositores (Montevideo: Imprenta de El Nacional, 1843).

29 El Nacional (Montevideo, 26 de febrero de 1844), 3.

30 El diario, fundado por el político, diplomático e historiador Andrés Lamas, tuvo dos épocas. La primera entre 1835 y 1836 en que fue clausurado por el gobierno de Oribe; la segunda etapa se inició en 
noticias que buscaron presentar al ejército sitiador como un ámbito donde imperaba la falta de moralidad, los crímenes más terribles (fusilamientos, asesinatos, mutilaciones y hasta canibalismo ${ }^{31}$ ) y un espacio en el que era difícil establecer el límite entre autoridades y delincuentes. Esa visión sobre la delincuencia y los métodos de terror también se trasluce en algunas órdenes y disposiciones del período. Un decreto del 13 de febrero de 1843 -en forma previa a que comenzara el sitioestablecía que "el Ejército titulado de la Confederación Argentina, que pisa el Territorio de la República, está compuesto casi en su totalidad de gentes allegadas por el terror y los medios violentos" 32 . Ese dato -un elemento más de un enfrentamiento en el peor momento del asediolleva a mirar esas acusaciones pueden ser pistas interesantes para tratar de seguir derroteros militares de hombres con un pasado delictivo.

Como ha señalado Rabinovicih "[c]ada desertor significaba un rudo golpe para el ejército" ya que "no sólo se perdía un hombre, sino que cundía el ejemplo de la desobediencia"33. En los casos comentados por La Gaceta o El Nacional la situación no solo involucraba a la deserción, sino al pasaje hacia el bando enemigo, por lo que la "traición" era doble y triple si agregamos que se trató de hombres con causas criminales aún abiertas. El paso desde un ejército hacia otro era una amenaza no solo por el abandono del puesto, sino que era una posibilidad de acceder a información estratégica sensible para quienes recibían a los fugados, al tiempo que un cuestionamiento al gobierno de la defensa, que, en una situación compleja, perdía legitimidad.

En los primeros dos años del asedio a la ciudad las órdenes que buscaban mantener la disciplina fueron numerosas y firmes. Distintas disposiciones buscaron censurar las "infidencias" o directamente todo tipo

1838 con el ingreso de Fructuoso Rivera a Montevideo y finalizó en 1846. Durante el sitio de la ciudad José Rivera Indarte fue puesto al frente de la publicación, que también contó con la colaboración de otros emigrados "argentinos" como Bartolomé Mitre, Esteban Echeverría o Francisco Agustín Wright. Daniel Álvarez Ferretjans, Historia de la Prensa en el Uruguay (Montevideo: Búsqueda-Fin de Siglo, 2008), 124-127.

3431 Mario Etchechury, "Visto y oído", 89.

32 Pedro de León, Recopilación de decretos militares desde el año 1828 hasta 1889 (Montevideo: Tipografía de la Escuela Nacional de Artes y Oficios, 1889, tomo I), 271.

33 Alejandro Rabinovich, "La imposibilidad", 37. 
de contacto con el bando enemigo (por ejemplo, pasar bienes o armas al enemigo era penado con la muerte). Esto se debía, sobre todo, a que la previsión sobre posibles enemigos internos que intentaban "debilitar" a la ciudad, llevó a que los mandos montevideanos insistieran en la necesidad de mantener una tropa unida y disciplinada.

Al mismo tiempo castigaron la deserción a través de la participación de comisiones militares encargadas de juzgar y penar a los soldados que salían de la línea defensiva ${ }^{34}$. El gobierno de la defensa estableció que serían "irremisiblemente pasados por las armas todos los individuos del Ejército de Rosas que sean aprehendidos y pertenezcan a la clase de jefes y oficiales" ${ }^{35}$. Aunque el 14 de noviembre de 1844 se ofreció indulto a "[t]odo ciudadano Oriental desde la clase de Jefe hasta la de soldado, perteneciente al Ejército invasor que se presente" e incluso su consideración "en la clase que gozaba en las filas enemigas". En el caso de los argentinos también se respetaría la vida, pero se los obligaría a salir del territorio de Montevideo en dirección a Buenos Aires, salvo que en forma expresa manifestaran su voluntad de integrar las filas militares de la defensa ${ }^{36}$.

\section{Circulación de desertores, Redes militares y pasos hacia el BANDO ENEMIGO}

La situación se torna más compleja si agregamos la referencia al legajo judicial de Francisco Real. Aunque se buscaron distintos expedientes sólo fue posible encontrar el de Real, acusado de asesinar a su vecino Francisco Vera ${ }^{37}$. La causa aporta más datos sobre Real, pero también sobre las distintas formas de reclutamiento militar utilizadas en este caso por el gobierno de la defensa.

Real, santafecino, de 52 años y casado, apuñaló y asesinó en junio de 1842 a Vera. El motivo era, según testimonio del encausado, una dispu-

34 Pedro de León, Recopilación de decretos, 256, 257 y 263, 264.

35 Decreto del 8 de octubre de 1843, véase Pedro de León, Recopilación de decretos, 296.

36 Pedro de León, Recopilación de decretos, 309.

37 "Juzgado del Crimen contra Francisco Real por el homicidio de Francisco Vera", en Archivo General de la Nación (AGN), Juzgado del Crimen, expediente número 83/1842. 
ta económica que mantenía con su vecino por una deuda de quinientos pesos. Al parecer tanto Real como Vera participaban del tráfico de objetos robados hacia la platería de Nicolás García y otra cuyo propietario se apellidaba Martínez (el nombre es ilegible en el documento ya que está tachado).

El 7 de febrero de 1843 por orden de la Jefatura Política y de Policía de Montevideo y con anuencia del Juez del Crimen, Real, junto al preso Mauricio Pintos, fue puesto en libertad e incorporado a la línea defensiva. El 22 de mayo del mismo año la causa por asesinato fue archivada. Podríamos pensar que la incorporación al ejército era una forma de purgar la pena, pero también parte de un acuerdo no escrito, que favorecía a las personas contraventoras de las leyes penales para "sanear" su historial.

Finalmente, el 2 de febrero de 1844 Real y un soldado de apellido Lozano "del $6^{\circ}$ Batallón de Línea" pasaron al enemigo ${ }^{38}$. El 5 de febrero el $6^{\circ}$ Batallón de Infantería, comandado por Marcelino Sosa, sufrió una nueva deserción, por lo que el tránsito realizado por Real y Lozano fue solo un anticipo de lo que ocurrió tres días más tarde ${ }^{39}$; los fugados y pasados al Cerrito fueron el oficial Eustaquio Chalar, el cabo, Juan Ramos y el soldado, Bernardino Nabeira -cuyos expedientes no fue posible ubicar- quienes probablemente también contaran con contactos que permitieron trasladar y acoger a un importante número de hombres. El Batallón de Marcelino Sosa (quien murió en combate el 8 de febrero de 1844) no era una división tradicional, sino que se encargaba de realizar guerra de guerrillas en la línea sitiadora. Son varios los testimonios en esa dirección ${ }^{40}$ y no sería extraño pensar que esas tareas de riesgo fueran cumplidas por antiguos convictos como Real. Según el comentario de Félix San Martín -en base a las memorias de su abuelo Francisco San Martín integrante de la Legión Argentina- la división de Sosa formaba parte de las llamadas escuchas, integrada por 350 hombres divididos en seis grupos. La riesgosa tarea de las escuchas era "cubrir la línea exterior

38 Archivo General de la Nación (AGN), Ministerio de Guerra y Marina (en adelante MGM), caja 1352.

39 AGN, Ministerio de Guerra y Marina, caja 1352.

40 Véase Eduardo Acevedo, Anales Históricos, 115. 
de la defensa durante la noche, apoyadas por tres cantones fortificados" levantados en el centro y en los dos extremos de las barricadas defensivas. El flanco izquierdo era cubierto por la división al mando del coronel Sosa ${ }^{41}$.

Un denominador común en la situación de Real es la figura de Andrés Lamas. Durante 1842 Lamas se desempeñó como Juez del Crimen (era un juzgado de carácter "nacional" asentado en Montevideo) y en febrero de 1843 -y hasta mayo de 1844- se encargó de la jefatura política y de policía de Montevideo ${ }^{42}$ responsable de la defensa de la ciudad. La doble condición de juez del crimen y jefe político, nos lleva a pensar que la liberación de presos fue una estrategia utilizada por las autoridades para contar con mayor número de hombres en armas, en especial en la infantería. No sería de extrañar que Lamas estuviera al frente de esa estrategia, ya que tanto en su condición de juez como jefe de policía conocía la situación de todos los presos y encausados y probablemente tuviera trato directo con varios de ellos.

En agosto de 1843 Lamas presentó un proyecto de reforma penitenciaria en el que abogó por el trabajo de los penados ${ }^{43}$. La idea de Lamas era que los penados sin ningún tipo de oficio conocido pudieran cumplir tareas en el servicio público. El proyecto no es explícito sobre cuáles serían las tareas, aunque podríamos pensar que esa especie de amnistía permitió la incorporación a las líneas defensivas a convictos como soldados. No contamos con cifras de presos para el período del sitio, así como carecemos de información sobre la cantidad y la calidad de los delitos, pero ante la necesidad de hombres y la urgencia de la situación, es dable sostener que un importante número de presos por diversos delitos terminaron incorporándose a filas del ejército.

41 Félix San Martín, Episodios del sitio de Montevideo. 1843-1851 (Buenos Aires: Biblioteca del Suboficial, 1925), 51.

42 Andrés Lamas al ministro de Gobierno (5 de febrero de 1843), AGN, MG, caja 943, carpeta 3A, documento 272.

43 Horacio Arredondo (hijo), Los "Apuntes estadísticos" del Dr. Andrés Lamas, Montevideo: El Siglo Ilustrado, Apartado de la "Revista del Instituto Histórico y Geográfico del Uruguay", Vol. VI No. 1, (1928): 149-151. 
En la papelería consultada, las disposiciones que remitieron presos al ejército se sucedieron durante el sitio y también en forma previa a que se iniciara el asedio de la ciudad. Por ejemplo, el 13 de febrero de 1843, por disposición de Lamas, Manuel Fernández fue enviado como castigo al ejército de operaciones, para revestir como soldado del escuadrón de vanguardia, por haber proferido insultos en forma pública a Fructuoso Rivera $^{44}$. Casos como el de Real o Fernández no fueron excepciones sino la norma, en un contexto en el cual la necesidad de hombres para el frente, en especial para la línea sitiadora, se tornaba acuciante.

En el gobierno del Cerrito también utilizó el apresamiento y eventual procesamiento judicial como motivo para incorporar hombres al ejército. Por ejemplo, el 27 de setiembre de 1843 Dionisio Pérez fue enviado a la fuerza de línea tras robar y carnear una vaca; por su parte Bernardo Martínez, natural de Canarias, fue destinado por la policía a la compañía del capitán Ramón Suárez, de la cual desertó y fue apresado nuevamente y enviado el 16 de noviembre de 1843 a cumplir tareas en la línea sitiadora. Esta información se obtiene de las distintas comunicaciones de Juan Lasala uno de los principales referentes políticos y militares del ejército sitiador ${ }^{45}$. Las referencias al ejército apostado en el Cerrito son relevantes porque varios de los hombres que estamos siguiendo pasaron hacia esa zona. La afluencia de personas fue tal que había carencias de información básica sobre los hombres que conformaban las distintas divisiones, lo que da cuenta que los antecedentes biográficos o judiciales de quienes se incorporaban a sus filas no eran, en ese momento, motivo de mayor preocupación.

Resulta tentador pensar que la afluencia masiva de hombres a través de distintos mecanismos de reclutamiento, llevó a que fuera más relevante contar con brazos para la guerra que contar con datos filiatorios -en una época donde algo así era difícil- para identificar a los distintos individuos que componían los batallones. Algunos casos como los mencionados contribuyen a entender cuáles fueron las estrategias de recluta-

44 “Andrés Lamas al Jefe Político y de Policía de Montevideo", AGN, MG, caja 943, documento 289.

45 AGN, Gobierno del Cerrito, caja 1651. 
miento militar y cuáles fueron las consecuencias de la incorporación de los presos a los ejércitos en uno y otro lado.

El 6 de febrero de 1844 José María Paz, comandante en jefe del Ejército de Reserva sitiado en Montevideo, insistió en la necesidad de aumentar el número de hombres que estaban haciendo la guerra, aunque alertó con cierta preocupación que ese aumento implicaba incorporar individuos cuya conducta presagiaba "funestos resultados". En esa dirección, el 23 de enero de 1844 se dirigió a Lamas para reprochar el rol de la policía en el reclutamiento militar y la falta de preparación de quienes se incorporaban a la fuerza. En el texto Paz no alude directamente al ingreso de delincuentes, la crítica venía en la línea de lo que planteó en forma más explícita en febrero sobre la relación entre algunos soldados y la falta de moralidad ${ }^{46}$. Es probable que las personas apresadas e incluso juzgadas, fueran enviadas a los batallones como motivo de reforma (situación no privativa del período histórico aquí analizado) ${ }^{47}$. El fenómeno del reclutamiento no puede ser explicado en este contexto solo como consecuencia de las estrategias disciplinares. Sería importante sopesar la incidencia en la conformación de fuerzas en armas distintos factores y elementos que fueron constituyendo los ejércitos de los grupos políticos en pugna (a los cuales, también importa aclarar, resulta difícil observar como espacios homogéneos) $)^{48}$. Por tanto, es importante tomar en cuenta la necesidad de hombres para la guerra y la existencia de circuitos clandestinos por los que circularon soldados que pasaron de un bando a otro.

46 AGN, MGM, caja 1351. Sobre los intentos de Paz por disciplinar a la tropa, en especial al comienzo del sitio, véase José María Paz, Memorias póstumas (Buenos Aires: Trazo, 1950, vol. II). Sobre los enfrentamientos entre Paz y Rivera relativos a la organización de la guerra véase César Díaz, Memorias del Gral. César Díaz, 26.

47 La visión consolidad en la historiografía uruguaya que relaciona disciplinamiento y ejército en José Pedro Barrán, Historia de la sensibilidad en el Uruguay. La cultura "bárbara" (1800-1860) (Montevideo, Ediciones de la Banda Oriental, 1990, Vol. I) 55, 56.

48 Para comprender las estrategias de reclutamiento y disciplinamiento seguimos el análisis de Ricardo Salvatore sobre el período rosista. Véase Ricardo Salvatore, "Reclutamiento militar, disciplinamiento y proletarización en la era Rosas", Boletín del Instituto de Historia Argentina y Americana "Dr. Emilio Ravignani", No. 5 (1992): 25-47. 


\section{INTERMEDIARIOS}

Otro aspecto que se podría destacar es la posible participación de intermediarios que hicieron del pasaje de personas hacia la zona sitiadora un recurso comercial importante. No sería descabellado manejar como hipótesis de trabajo que esos intermediarios aprovecharon la situación de inestabilidad política y social y la necesidad de brazos para la guerra en las fuerzas sitiadas y sitiadoras para hacer un negocio.

Esta situación involucró intermediarios en distintos niveles. Entre ellos diplomáticos extranjeros, los cuales, según Andrés Lamas, llevaban adelante un "insoportable e inmoral abuso" mediante la expedición de certificados a "personas que no tienen la nacionalidad que ellos se dan"49. El caso más sonado fue el del cónsul portugués Leonardo de Souza Leitte Azevedo quien en octubre de 1843 fue expulsado de Montevideo acusado de ser espía rosista y de colaborar con la deserción de soldados a través de la entrega de papeletas de ciudadanía portuguesa a personas que no tenían esa nacionalidad ${ }^{50}$. A modo de ejemplo, el 11 de enero de 1844 fue detenido José C. Beijar, perteneciente al batallón Uruguay, quien "con papeleta portuguesa trataba de sacar pasaporte p.a. Bs. A.s". Según la declaración de Beijar la deserción había sido instigada y facilitada por Leitte ${ }^{51}$.

De acuerdo al decreto del 10 de febrero de 1843 todos los que "inciten a la deserción o la favorezcan de cualquier modo" serían apresados y juzgados por una comisión militar, que tenía potestades para condenarlos a muerte. Sus cómplices serían "juzgados militarmente" y "penados con el rigor que demande la gravedad del caso" 52 . El 12 de febrero un nuevo decreto estableció que "abandonar las filas del Ejército en los momentos en que la Patria está en peligro es el mayor de los delitos"

49 AGN, Policía de Montevideo, año 1843, caja 2.

50 "Declaración y acuerdo del gobierno de la República por la cual se suspende el execúatur dado al nombramiento del Cónsul General de Portugal en la República D. Leonardo de Souza Leitte”, Juan Pivel Devoto, Libro de Acuerdos, Decretos e Instrucciones del Ministerio de Relaciones Exteriores (1829-1851), (Montevideo: Ministerio de Relaciones Exteriores / Instituto Artigas del Servicio Exterior, 1990, Vol. I), 173, 174.

51 AGN, MG, caja 951, carpeta 4A.

52 Pedro de León, Recopilación de decretos, 257. 
por lo que era necesario castigarlo "con severidad", lo que incluía "la pena de muerte" para todos los "desertores que fueren aprehendidos [desde] ocho días después de la publicación [del] decreto" "53. En la papelería relevada no fue posible encontrar casos de penados a muerte por participar de redes de deserción ${ }^{54}$. En principio, la posibilidad de ser condenado a muerte no amilanó a los integrantes de esas redes.

El caso de Souza Leitte no fue el único; durante el período resultó frecuente la detención de hombres y mujeres que buscaban "la extracción de desertores y seducción de soldados", tal como sostenía un documento de noviembre de $1843^{55}$. Es probable que en el pasaje desde un bando hacia otro incidiera cierta idea según la cual las condiciones de vida en el Cerrito eran mejores a las de una ciudad sitiada con una perspectiva incierta. Los intermediarios hicieron que las deserciones no se dieran de manera fortuita o en función de intereses personales. Buena parte de las deserciones, como la de la guerrilla de Marcelino Sosa, ocurrieron en grupo y con cierto grado de conocimiento previo entre quienes escapaban de un punto hacia otro.

Los intermediarios hacían una especie de juego doble, tanto sacando hombres de Montevideo al Cerrito, como en el camino inverso. Esta posibilidad se refuerza si tomamos en cuenta las anotaciones del coronel Ramón Lista Viamonte, quien, en su diario de la guerra, llevado entre 1844 y 1851, contó casi a diario el número de militares que pasaban desde el Cerrito hacia Montevideo. Entre agosto 1844 y setiembre de 1851 desertaron del Cerrito y se presentaron en Montevideo, 825 personas. No se trata del total de desertores, sino solo aquellos que se presentaron ante las autoridades de la defensa, aunque el número es

53 Pedro de León, Recopilación de decretos, 260.

54 Tampoco en los casos de robos al Estado. Un ejemplo es el de Nicolás Parapán, pulpero de la zona de Las Bóvedas, en el puerto de la ciudad, en cuyo negocio fueron encontradas veintinueve pipas de pólvora al parecer vendidas por "marineros" argentinos. Detenido en mayo de 1843 fue liberado el 11 de julio del mismo año luego de pagar la fianza correspondiente. El robo de material bélico al Estado también estaba penado con la muerte. AGN, JCPT, Nicolás Parapán por haber comprado cantidad de pólvora robada al Estado, expediente número 53. Aunque hubo otros casos sonados, como el de Luis Baena, acusado de espionaje y conspiración y fusilado en octubre de 1843.

55 "Andrés Lamas al ministro de Gobierno, Santiago Vázquez", AGN, MG, caja 948, carpeta 3, Departamento de Policía, documento 256. 
significativo. En algunos casos Lista Viamonte señala que esos hombres pertenecían al ejército de la defensa, que desertaron al Cerrito y que regresaban a Montevideo ${ }^{56}$. Estas situaciones reafirman el carácter zafral de la participación militar y la ausencia de una inclinación ideológica precisa, ya que varios hombres hicieron la guerra en un bando u otro persiguiendo un interés económico y no siempre político. Al mismo tiempo contribuyen a desarmar la mirada tradicional sobre los ejércitos participantes en estas conflagraciones como estructuras homogéneas y que sirvieron como punto de partido a formaciones de carácter y dimensión nacional.

La existencia de intermediarios nos lleva a pensar en probables circuitos de la deserción, encabezados por hombres que se encargaban de sacar soldados hacia los barcos, legaciones extranjeras o territorio enemigo. Tal es el caso de Isidro Osorio, quien en 1844 fue apresado por conducir a soldados de origen vasco y español hacia el campo enemigo. Marcos Santos, uno de los españoles que había fugado, declaró que Osorio contaba con caminos que permitían salir de la capital ${ }^{57}$. En abril de 1843 la policía detuvo a un francés de apellido Dupuy, sospechoso de estar realizando "seduccion a favor del Ejto. que asedia esta capital"58, en un caso que salpicó incluso al cónsul francés en Montevideo, quien a fines de 1843 se retiró de la ciudad. En junio del mismo año quedó en evidencia una red que a través de la intervención del "corredor" Pedro Buboni conseguía pasaportes que eran entregados a supuestos "extranjeros" que pasaban por franceses. Por último, en noviembre de ese primer año del sitio, Lamas inició en la justicia criminal un expediente "sobre la extracción de desertores y seducción de soldados de color" 59 .

56 Ramón Lista Viamonte, Diario de la Guerra Grande [1844-1851] (Montevideo: Dirección General de Extensión Universitaria, División Publicaciones y Ediciones, 1983).

57 "Sumario mandado levantar sobre la fuga de algunos individuos de tropa y seducción empleada para ello por Don Isidro Osorio" (12 de diciembre de 1844), AGN, JCPT, expediente 43; Policía de Montevideo, caja 1.

4258 "Andrés Lamas al Ministro de Relaciones Exteriores y Gobierno, Montevideo, 14 de abril de 1843", AGN, MG, caja 944, carpeta 5.

59 "Montevideo, 28 de noviembre de 1843, Andrés Lamas al juez del crimen”, AGN, MG, caja 948, documento 256. 
La relación entre los soldados/delincuentes y las deserciones hacia el Cerrito, se refuerza si tomamos en cuenta que en enero de 1844 -mes en el que se produjeron las fugas de Real y Guerrero- quedó en evidencia una red de deserción que funcionaba dentro de la cárcel comandada por un hombre de apellido Pascualini ${ }^{60}$. El indagado contaba con un cómplice, de apellido Lacubesos o Lacubaros, conductor de un barco que vivía en el Buceo y cuya detención se solicitó por motivos de indagación. Lamentablemente en la papelería consultada no sabemos qué ocurrió con esas indagaciones y tampoco fue posible encontrar un expediente judicial referente a alguno de los apellidos mencionados.

La zona del Buceo, en especial su puerto, resultó durante la guerra un espacio conflictivo y utilizado por numerosos enemigos políticos de Montevideo para pasar personas, información y también contrabandear mercaderías. El pasaje de personas -no sólo desertores- a través de la zona del Buceo resultó frecuente durante todo el período que duró el sitio, aunque fue más intenso en los dos primeros años del asedio a la ciudad. Pero más allá del rol estratégico del Buceo, podríamos plantear como una conjetura que Pascualini organizaba las deserciones desde la prisión para aquellos penados que se iban a incorporar a la línea defensiva. A través de contactos -en los que probablemente también estuviera involucrado un guardia de la cárcel del Cabildo- lograba coordinar con uno o más de sus cómplices que se encontraban en el Buceo.

Como señaló Bruno Latour cualquier red social está formada por hechos, pero también por vacíos que permiten un abordaje parcial de reconstrucción ${ }^{61}$. No fue posible dar con el expediente judicial de Pascualini, o alguno que lo involucre, pero la fecha en la que esa supuesta red fue desbaratada coincide con la deserción de Francisco Real y su pasaje al Cerrito. Como se señaló, Real era un delincuente común preso por un asesinato, presuntamente indultado para incorporarse a un batallón de la línea defensiva. No sería extraño que personas como Real tuvieran un contacto previo con un intermediario (Pascualini u otro) que facilitó

60 AGN, MG, caja 951, carpeta 5.

61 Bruno Latour, Reensamblar lo social. Una introducción a la teoría del actor-red. (Buenos Aires: Manantial, 2008). 
su pasaje a territorio enemigo. Aunque se trata de conjeturas, durante, al menos, los dos primeros años del sitio se discutió sobre la existencia de redes o grupos de conspiradores, entre los que se encontraban aquellos que facilitaban la deserción.

\section{Consideraciones FinAles}

Los casos a los que hemos logrado acceder son aquellos que cobraron notoriedad por denuncias en la prensa o porque los desertores fueron apresados y eventualmente juzgados, o aquellos que generaron tensiones que provocaron una crisis pública. Pero podríamos preguntarnos cuántos hombres logaron evadir los controles y pasaron al bando enemigo sin que sus nombres quedaran asentados en un expediente militar, policial o judicial (de cualquier fuero). A su vez, pensar en el rol que le cupo a estos soldados con un pasado delictivo resulta interesante para comenzar a analizar desde otra óptica de qué modo se conformaron los cuadros más bajos de los ejércitos participantes del conflicto que durante casi quince años rigió los destinos de varias de las provincias del Río de la Plata.

Las pistas con que contamos son dispersas y fragmentarias ${ }^{62}$; en las memorias de los militares más destacados de la época podemos ver el malestar ante la falta de preparación y disciplina. Pero el tema de los delincuentes militarizados no siempre aparece mencionado en forma explícita. La ausencia de un señalamiento a ese tipo de situaciones no anula el problema que contribuye a complejizar cada vez más el período de la Guerra Grande.

Casos como los expuestos ayudan a entender la situación entre la soldadesca, al tiempo que resultan de interés para ver cuáles fueron las estrategias impuestas en uno u otro bando para reclutar hombres. En el caso de Montevideo pudimos ver cómo con la presunta anuencia del jefe político de la ciudad, Andrés Lamas, se aprobó la participación de

62 Salvo las declaraciones publicadas por los diarios utilizados, que podríamos considerar mediatizadas, no fue posible acceder a testimonios de algunos de los soldados implicados. 
delincuentes comunes enviados al peor lugar del sitio, la línea defensiva, primer punto de contacto entre los atacantes y los defensores de Montevideo.

Por su parte, el gobierno del Cerrito llevó adelante distintas estrategias que buscaron desestabilizar el interior de la ciudad sitiada. Ataques directos, rumores, sabotajes y la promoción de la deserción entre las filas del ejército. Allí es que cumplieron un rol fundamental los intermediarios que se movieron en varios niveles, tratando de seducir a legionarios nacionales, pero también a delincuentes militarizados.

El artículo intentó ser un ejercicio historiográfico que buscó encontrar una forma distinta de mirar la formación de fuerzas en armas, por lo general signadas por relatos nacionales que presentan a los ejércitos como estructuras unificadas y homogéneas. A su vez permite individualizar algunos casos que, por lo general, quedan anulados en discusiones mayores relativas a la conformación de grandes estructuras militares.

La Guerra Grande fue para la región platense uno de los conflictos más importantes del siglo XIX, en el que participaron numerosos ejércitos (incluso armadas extranjeras), un enfrentamiento que devastó la haciendas y movilizó grandes grupos poblacionales. La historiografía uruguaya más tradicional se ha concentrado en dar cuenta de las batallas, de los debates públicos, sin tratar de encontrar miradas a ras del suelo que resultan interesantes para cuestionar y comprender algunos rasgos del conflicto.

Al estudiar algunos casos, en una perspectiva que intenta desentrañar redes y salir de los esquemas clásicos de las distintas formas de hacer la guerra, nos podemos acercar un poco más a historias de vida, situaciones no consideradas, pero que también resultan fundamentales para entender esas sociedades movilizadas en torno a la guerra durante buena parte del siglo XIX. Las reconstrucciones realizadas en el texto sobre esos soldados/delincuentes/desertores resultan provisorias y fragmentarias, pero el ejercicio historiográfico de manejar las fugas 
como una posibilidad, las biografías como algo probable, las redes de deserción como algo factible y encontrar una dimensión histórica hasta ahora no considerada, es una enorme tentación para el historiador actual.

\section{BibliografíA}

\section{Fuentes primarias}

Archivo General de la Nación (AGN), Montevideo - Uruguay, Documentos de la Administración Central, Ministerio de Gobierno.

Archivo General de la Nación (AGN), Montevideo - Uruguay, Gobierno del Cerrito.

Archivo General de la Nación (AGN), Montevideo - Uruguay, Ministerio de Guerra y Marina.

Archivo General de la Nación (AGN), Montevideo - Uruguay, Policía de Montevideo.

Archivo General de la Nación (AGN), Montevideo - Uruguay, Sección Judicial. Juzgado del Crimen del Primer Turno.

\section{Publicaciones periódicas}

El Nacional. Montevideo, 26 de febrero de 1844.

La Gaceta Mercantil. Diario comercial, político y literario. Buenos Aires, 12 de febrero de 1844 .

\section{Fuentes secundarias}

Arredondo, Horacio. Los “Apuntes estadísticos” del Dr. Andrés Lamas. Montevideo: El Siglo Ilustrado, Apartado de la "Revista del Instituto Histórico y Geográfico del Uruguay", n 1 vol. VI, número 1 (1928).

de Iriarte, Tomás. El sitio de Montevideo y la política internacional en el Río de la Plata. Buenos Aires: Ediciones Argentina, 1951.

de León, Pedro. Recopilación de decretos militares desde el año 1828 hasta 1889. Montevideo: Tipografía de la Escuela Nacional de Artes y Oficios, 1889, tomo I.

Díaz, César. Memorias del Gral. César Díaz. Montevideo: Ministerio de Instrucción Pública, 1968. 
Lista Viamonte, Ramón. Diario de la Guerra Grande [1844-1851]. Montevideo: Dirección General de Extensión Universitaria, División Publicaciones y Ediciones, 1983.

Magariños de Mello, Mateo. El Gobierno del Cerrito. Montevideo: s.d., 1961, tomo II.

Paz, José María. Memorias póstumas. Buenos Aires: Trazo, 1950, vol. II.

Pivel Devoto, Juan. Libro de Acuerdos, Decretos e Instrucciones del Ministerio de Relaciones Exteriores (1829-1851). Montevideo: Ministerio de Relaciones Exteriores / Instituto Artigas del Servicio Exterior, 1990, vol. I.

Rivera Indarte, José. Rosas y sus opositores. Montevideo: Imprenta de El Nacional, 1843.

San Martín, Félix. Episodios del sitio de Montevideo. 1843-1851. Buenos Aires: Biblioteca del Suboficial, 1925.

[Wright, Francisco Agustín]. Montevideo. Apuntes históricos de la defensa de la república. Montevideo: Imprenta del Nacional, 1845. Abadie-Aicardi, Oscar. "Levas y deserciones de marineros extranjeros en los orígenes de la Armada Nacional (1830-1840)". Humanidades. Revista de la Universidad de Montevideo n 3, 2003: 75-109.

Acevedo, Eduardo. Anales históricos del Uruguay. Montevideo: Barreiro y Ramos, 1933, vol. II.

Álvarez Ferretjans. Daniel. Historia de la Prensa en el Uruguay. Montevideo: Búsqueda-Fin de Siglo, 2008.

Barrán, José Pedro. Historia de la sensibilidad en el Uruguay. La cultura "bárbara" (1800-1860). Montevideo: Ediciones de la Banda Oriental, 1990, vol. I.

Blok, Anton. "The Peasant and the Brigand: Social Banditry Reconsidered". Comparative Studies in Society and History, vol. 14, n. 4 (1972): 494-503.

Borucki, Alex. From Shipmates to Soldiers: Emerging Black Identities in the Rio de la Plata. Albuquerque: University of New Mexico Press, 2015.

Etchechury, Mario. "De colonos y súbditos extranjeros a «ciudadanos en armas». Militarización y lealtades políticas de los españoles residentes en Montevideo, 1838-1845". Revista Universitaria de Historia Militar, vol. 4 (2015): 119-142

Etchechury, Mario. "DDefensores de la humanidad y la civilización'. Las legiones extranjeras de Montevideo, entre el mito cosmopolita y 
la eclosión de las nacionalidades (1838-1851)". Historia, vol. 50, n .2 (2017): 491-524.

Etchechury, Mario. “'Chinas, guayaquises y jente que no es de armas'. Algunas consideraciones sobre el impacto social de la guerra en Montevideo y su hinterland rural (1842-1845)". Prohistoria, vol. 20, n. 28 (2017): 129-147.

Etchechury, Mario. "Aventureros, emigrados y cosmopolitas. Hacia una historia global de las guerras en el Río de la Plata (1836-1852)", Polhis, n 20 (2017): 22-52.

Etchechury, Mario. "“Visto y oído". El testimonio de los prisioneros de guerra: de la experiencia del combate a la propaganda bélica (Río de la Plata, 1839-1845)", en Laura Reali. Guerras civiles. Un enfoque para entender la política en Iberoamérica (1830-1935). Madrid: Estudios de AHILA, 2019: 89-106.

Fessler, Daniel. "Armas y control. El "negro delito de la deserción” en la Banda Oriental (1811-1816)", en Paulo Possamai, Emir Reitano. Hombres, poder y conflicto. Estudios sobre la frontera colonial sudamericana y su crisis. La Plata: Universidad Nacional de la Plata, 2015: 388-415.

Fessler, Daniel. "Desertores: entre el castigo y el indulto", en Ana Frega. Los orientales en armas. Estudios sobre la experiencia militar en la revolución artiguista. Montevideo: Universidad de la República, 2015: 29-53.

Frega, Ana. "La vida política", en Historia contemporánea del Uruguay. 1808-1880. Montevideo: Fundación MAPFRE-Planeta, 2016, vol. I.

Garavaglia, Juan Carlos, Juan Pro Ruiz, Eduardo Zimmermann. Las fuerzas de la guerra en la construcción del Estado: América Latina, siglo XIX, Rosario: Prohistoria, 2012.

Grijó, Luis Alberto, Eduardo Santos Neumann. O continente em armas: uma historia da guerra no sul do Brasil. Rio de Janeiro: Apicuri, 2010,

Hobsbawm, Eric. Bandidos. Barcelona: Crítica, 2003.

Latour, Bruno. Reensamblar lo social. Una introducción a la teoría del actor-red. Buenos Aires: Manantial, 2008.

Meisel, Seth, "The Politics of Seduction: Mutiny and Desertion in Early Nineteenth-Century Cordoba”, en Jane Hathaway. Rebellion, Repression, Reinvention: Mutiny in Comparative Perspective. Westport: Praeger, 2001. 
Myers, Jorge. Orden y virtud. El discurso republicano en el régimen rosista. Buenos Aires: Universidad Nacional de Quilmes, 1995.

O’Malley, Pat. "Social Bandits, Modern Capitalism, and the Traditional Peasantry: A Critique of Hobsbawm". Journal of Peasant Studies, vol. 6, n. 4 (1979) 489-501.

Pivel Devoto, Juan E. Historia de los partidos políticos en el Uruguay. Montevideo, Atlántida: 1942, tomo I.

Pivel Devoto, Juan. E, Alcira Ranieri de Pivel Devoto. La Guerra Grande. 1839-1851. Montevideo: Medina, 1971.

Rabinovich, Alejandro. "El fenómeno de la deserción en las guerras de la revolución e independencia del Río de la Plata: 1810-1829". EIAL, vol. 22, n 1 (2011): 33-56.

Rabinovich, Alejandro. "La imposibilidad de un ejército profesional: Ramón de Cáceres y el establecimiento de procedimientos burocráticos en las fuerzas del Río de la Plata. 1810-1830”. Quinto Sol, vol. 17, n 1 (2013) https://cerac.unlpam.edu.ar/index.php/ quintosol/article/view/597

Rabinovich, Alejandro. La société guerrière. Pratiques, discours et valeurs militaires dans le Rio de la Plata, 1806-1852. Rennes: Presses Universitaires de Rennes, 2013.

Salvatore, Ricardo. "Reclutamiento militar, disciplinamiento y proletarización en la era Rosas". Boletín del Instituto de Historia Argentina y Americana "Dr. Emilio Ravignani”, n 5 (1992): 25-47.

Slatta, Richard. Bandidos. The varieties of Latin American Banditry. New York: Greenwood Press, 1987.

Thul, Florencia. "Mercado de trabajo y movilización militar en Montevideo sitiada (1838-1851)". Claves. Revista de Historia, vol. 5, n. 8 (2019): 7-34.

Zinny, Antonio. La Gaceta mercantil de Buenos Aires 1823-1852 resumen de su contenido con relación a la parte americana y con especialidad á la historia de la República Argentina. Buenos Aires: Imprenta Americana, 1875.

Para citar este artículo: Duffau Soto, Nicolás. "Los "hombres funestos". Soldados delincuentes, redes de deserción y guerra política durante los dos primeros años del Sitio Grande de Montevideo (18431844)", Historia Caribe Vol. XV No. 36 (Enero-Junio 2020): 21-49. DOI: http://dx.doi.org/10.15648/hc.36.2020.3 